\title{
Aves do eixo rodoviário do plano piloto de Brasília
}

A urbanização transforma os ecossistemas nativos e afeta negativamente a flora e a fauna. Apesar dos problemas, as aves podem fazer das cidades um refúgio e desempenhar funções ambientais. Espera-se que a arborização viária tenha relações positivas coma riqueza, diversidade e abundância de espécies de aves em áreas urbanas. Nesse cenário, Brasília é uma cidade parque, onde longos corredores verdes formados por estradas e ruas estão inseridos desde a sua concepção. Um exemplo é o Eixo Rodoviário do Plano Piloto de Brasília (Eixão), via de 14km que conecta as porções norte e sul da cidade, fundamental para a mobilidade urbana compondo um grande corredor verde. Este trabalho tem como objetivo identificar e descrever a comunidade de aves presente no Eixão. As aves foram amostradas em 32 pontos fixos ao longo da durante um ano. Resultados mostraram que 86 espécies de aves pertencentes a 36 famílias habitam a área pesquisada. Houve um predomínio em abundância das espécies Furnarius rufus, Columba livea, Brotogeris chiriri, Pitangus sulphuratus. Essas espécies de aves têm alta tolerância a modificações de habitat e podem fornecer importantes funções ecológicas nas cidades. A maioria das espécies que frequentam o Eixão são consideradas generalistas e oportunistas, originárias de áreas nativas campestres; elas são capazes de explorar a arborização urbana da cidade para obtenção de recursos. Este trabalho mostra que uma rua muito movimentada é capaz de reter uma parcela importante da diversidade de aves.

Palavras-chave: Cidades; Ruas; Arborização urbana; Generalistas; Aves urbanas.

\section{Birds of the highway axis of the Brasilia pilot plan}

Urbanization transforms natural ecosystems and negatively affects flora and fauna. Even tough, birds can make cities their refuge and carry out environmental functions. It is commonly believed that roads trees to have positive relationships richness, diversity and abundance of bird species in urban areas. In this scenario, Brasilia is a park city, where long green corridors formed by roads and streets have been inserted since its conception. An example is the highway axis of the Brasilia pilot plan (Eixão), $14 \mathrm{~km}$ away as northern and southern parts of the city, which is essential for urban mobility consisting of a large green corridor. This work aims to identify and characterize the bird community present in the Eixão. Birds were sampled at 32 fixed points for a year. Results showed that 86 species of birds belonging to 36 families inhabit the surveyed area.Furnarius rufus, Columba livea, Brotogeris chiriri, Pitangus sulphuratus were the most abundant species. These bird species have a high tolerance for habitat change and can provide important ecological functions in cities. Most of the species they frequent or Eixão are generalist and opportunistic species, originating from natural country areas. They are able to explore an urban tree lining of the city to explore resources. This work shows that a very busy street is able to retain a significant portion of bird diversity.

Keywords: Citys; Street; Urban trees; Generalists; Urban bird.

Topic: Desenvolvimento, Sustentabilidade e Meio Ambiente

Reviewed anonymously in the process of blind peer.
Received: 02/02/2020

Approved: $10 / 03 / 2020$

Mayara Machado Guimarães (iD)

Universidade de Brasília, Brasil

http://lattes.cnpq.br/0527371693483169

http://orcid.org/0000-0003-1019-6556

may.mguimaraes@gmail.com

João Carlos de Castro Pena (iD)

Universidade Estadual Paulista Júlio de Mesquita Filho, Brasil

http://lattes.cnpq.br/6010755596170093

http://orcid.org/0000-0003-1368-1805

joaocpena@gmail.com

Rodrigo Studart Corrêa (iD

Universidade de Brasília, Brasil

http://lattes.cnpq.br/4065757997691333

http://orcid.org/0000-0002-9422-2629

rodmanga@gmail.com

Referencing this:

GUIMARÃES, M. M.; PENA, J. C. C.; CORRÊA, R. S.. Aves do eixo rodoviário do plano piloto de Brasília. Revista Ibero Americana de Ciências Ambientais, v.11, n.2, p.333-349, 2020. DOI: http://doi.org/10.6008/CBPC2179-6858.2020.002.0031 


\section{INTRODUÇÃO}

A urbanização provoca mudanças no uso e cobertura do solo, nos ciclos bioquímicos, no clima local, nos sistemas hidrológicos e, sobretudo, na biodiversidade (GRIMM et al., 2008). Aves são particularmente afetadas pela urbanização de uma área, porque o ambiente urbano atua como um filtro ambiental (CROCl et al., 2008), resultando em alterações negativas para a avifauna (MCKINNEY, 2008; CHACE et al., 2006; ARONSON et al., 2014). A substituição de ecossistemas nativos por centros comerciais, casas, prédios, ruas e vias causa modificações na composição de espécies de aves (MARZLUFF et al., 2001; CROCI et al., 2008; MACGREGOR-FORS et al., 2011). Em escala global, existem evidências de que a urbanização induz declínios de riqueza e diversidade de aves (BLAIR, 1996; JOKIMÄKI et al., 1998; MELLES et al., 2003).

Entretanto, muitos táxons toleram a urbanização (CLERGEAU et al., 2006; CROCl et al., 2008), porque o nível de tolerância sobre a intensidade da urbanização difere entre espécies (SOL et al., 2013). Os padrões de tolerância urbana são pouco compreendidos, mas é aceito que algumas populações possuem flexibilidade comportamental (CHACE et al., 2006; SOL et al., 2013). Há muitas espécies de aves capazes de se adaptarem e explorarem as cidades (BIAIR, 1996; SOL et al., 2013), enquanto outras são sensíveis à urbanização e reduzem suas populações ou evitam áreas alteradas (MELLES et al., 2003). Essa dicotomia auxilia na compreensão das diferenças de composição entre comunidades de aves sensíveis a alterações de habitat e comunidades exploradoras ou adaptadas ao meio urbano (CROCl et al., 2008). Características da matriz urbana e a disponibilidade de recursos urbanos e vegetais são importantes para manter populações de aves generalistas, oportunistas e exploradoras (BLAIR, 1996; MCKINNEY, 2002; EVANS et al., 2009; 2011; MACGREGOR-FORS et al., 2012).

Nas cidades, a infraestrutura verde pode incluir uma variedade de opções, como os parques, praças, árvores urbanas, gramados, jardins e canteiros ao longo de avenidas e ruas (MORELLI et al., 2014). Esses ambientes podem abrigar a avifauna urbana e servir como corredor ecológico (FERNÁNDEZ-JURICI, 2000) ao conectar manchas verdes nativas circundantes (ESTEVO et al., 2017). A presença de cobertura vegetal pode fornecer locais de nidificação, forrageamento e proteção contra predadores (MCKINNEY, 2001). A importância da arborização de canteiros ao longo de ruas pode ser mostrada no estudo de Pena et al. (2017) em Belo Horizonte. Nele é demonstrado que a exposição ao ruído limitou a presença da avifauna nas ruas amostradas, mas locais com maior riqueza de espécies de árvores e maior proporção de espécies nativas, conseguiram reduzir os efeitos negativos do ruído. Em menor relevância, estruturas urbanas, como postes, linhas de transmissão e espaços residenciais, também são recursos (MACGREGOR-FORS et al., 2012; MORELLI et al., 2014). Espécies de aves sinantrópicas, por exemplo, são capazes de prosperar em paisagens urbanizadas, pois são pré-adaptadas e beneficiam de estruturas artificiais (CASE, 1996). Portanto, a heterogeneidade da paisagem pode ter um efeito positivo sobre a riqueza de aves, como resposta ao aumento de diferentes tipos de habitats que permitem a coexistência de espécies (SOUZA et al., 2019).

A capital brasileira, cidade planejada sob a concepção de cidade parque, possui grandes corredores verdes com árvores que podem conectar diferentes manchas verdes dentro de cidades e elas ao ambiente 
natural. Desde sua criação, a importância da arborização da cidade é ressaltada como meio de planejamento urbano, distribuição de setores e incremento da qualidade de vida (ALENCAR, 2008). Amplos espaços livres e intensa arborização são teoricamente aspectos positivos para comunidades de aves em Brasília. Nesse sentido, estudos anteriores identificaram 456 espécies de aves no Distrito Federal - DF (FARIA, 2008), incluindo 32 espécies endêmicas (SILVA et al., 2002). Sob esse cenário, o Eixo Rodoviário do Plano Piloto cruza toda a área residencial de Brasília e intercepta parte da escala monumental e gregária da cidade de norte ao sul. Essa estrutura viária é ladeada em todo seu percurso por fartos canteiros, que foram arborizados em diferentes épocas e sob diferentes paradigmas de arborização urbana (ALENCAR, 2008).

A expansão da malha urbana representa atualmente a principal ameaça à conservação da riqueza de aves em Brasília, porque ela elimina conexões entre áreas preservadas (CAVALCANTI et al., 2011). Agrava localmente esse fato a inexistência de estudos sobre a comunidade de aves na área urbana de Brasília em processo de fragmentação de remanescente de vegetação nativa. Em face do exposto, este trabalho objetivou identificar e caracterizar a comunidade de aves presente no Eixo Rodoviário do Plano Piloto de Brasília. Nossos resultados poderão ser utilizados para gerar informações sobre a qualidade ambiental do ambiente urbano e como os canteiros das ruas podem abrigar uma rica avifauna em um ambiente aparentemente hostil.

\section{MATERIAIS E MÉTODOS}

\section{Área de Estudo}

O trabalho foi conduzido no Eixo Rodoviário do Plano Piloto de Brasília (Eixão), Distrito Federal (Brasil). A capital brasileira se situa na parte central do Cerrado, originalmente coberta pelas quatorze fitofisionomias existentes no bioma, como áreas campestres e formações florestais (RIBEIRO et al., 2008). O clima predominante do Distrito Federal é o Tropical de Savana (Aw), de acordo com a classificação de Köppen-Geiger, com estações seca e chuvosa bem definidas. A precipitação média anual é de $1.668 \mathrm{~mm}$ e a temperatura média anual de $21.1^{\circ} \mathrm{C}$.

O Plano Piloto localiza-se no centro de Brasília, cujo o projeto urbanístico é composto por quatro escalas denominadas monumental, gregária, residencial e bucólica (LIMA et al., 2010). O Eixão foi planejado de dentro dos conceitos das duas últimas escalas, a residencial é formada por superquadras preenchidas por prédios residenciais e entrequadras com comércio local, permitindo acessibilidade e mobilidade dos pedestres em meio às árvores; a escala bucólica é representada pelas áreas verdes e arborizadas, que conectam edificações e demais escalas (ALENCAR, 2008). O Eixão é uma via de 14 km de extensão, que se estende na direção norte-sul e que cruza e une as duas partes da escala residencial da cidade: a Asa Sul e a Asa Norte (Figura 1). O Eixão é ladeado por canteiros de $45 \mathrm{~m}$ de largura, cobertos por gramados e espécies arbóreas nativas e exóticas ao Cerrado, praticamente todas em estado adulto. Os pontos fixos utilizados neste trabalho foram distribuídos ao longo dos canteiros leste e oeste do Eixão, os quais são ladeados por outras vias paralelas (Eixinhos) e vias de acesso (Tesourinhas) (Figura 1). Sua arborização é composta por 
espécies predominantemente ornamentais, frutíferas de médio e grande porte e algumas espécies de arbustos. Os canteiros arborizados ao longo do Eixão formam um corredor ecológico que cruza a parte central da cidade (Figura 2). A arborização urbana do Plano Piloto priorizou inicialmente o uso de espécies ornamentais exóticas do bioma Cerrado. A partir da década de 1980, espécies arbóreas nativas do Cerrado começaram a ser utilizadas na arborização da cidade, sobretudo na Asa Norte do Plano Piloto (LIMA et al., 2010). Em Brasília, alguns fragmentos de vegetação nativa foram mantidos na malha urbana (CAVALCANTI et al., 2011), inclusive nas proximidades do Eixão. Como exemplo, o Parque Olhos D'água, que apresenta corpos d'água, áreas brejosas e variadas fitofisionomias.

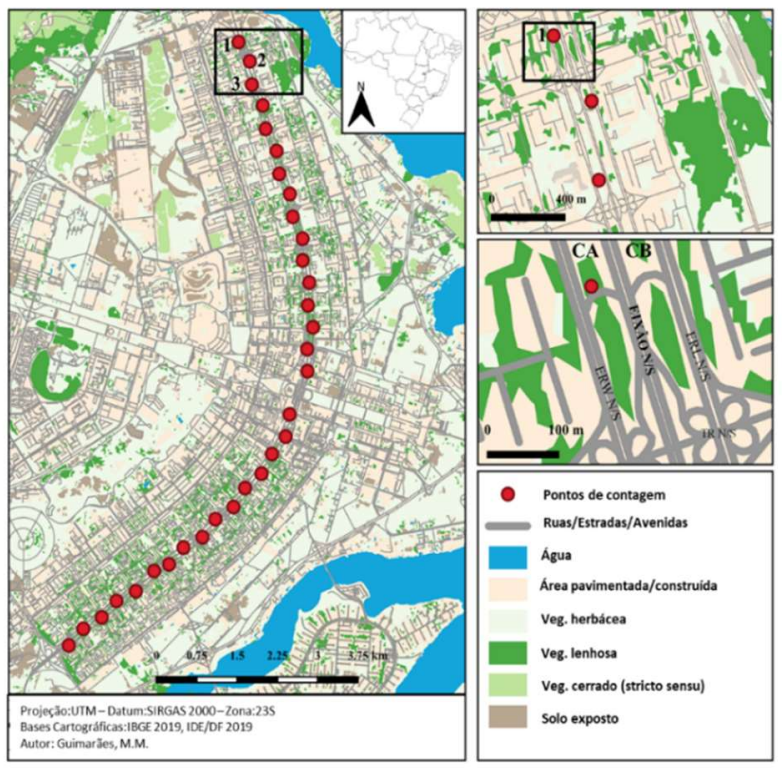

Figura 1: Mapa ampliado da cidade de Brasília (Distrito Federal, Brasil), mostrando a distribuição dos 32 pontos de contagem. Com destaque os canteiros do Eixão N/S. CA: Canteiro-A, CB: Canteiro-B, ERWN/S: Eixinho oeste, ERL: Eixinho leste, TRN/S: tesourinha.

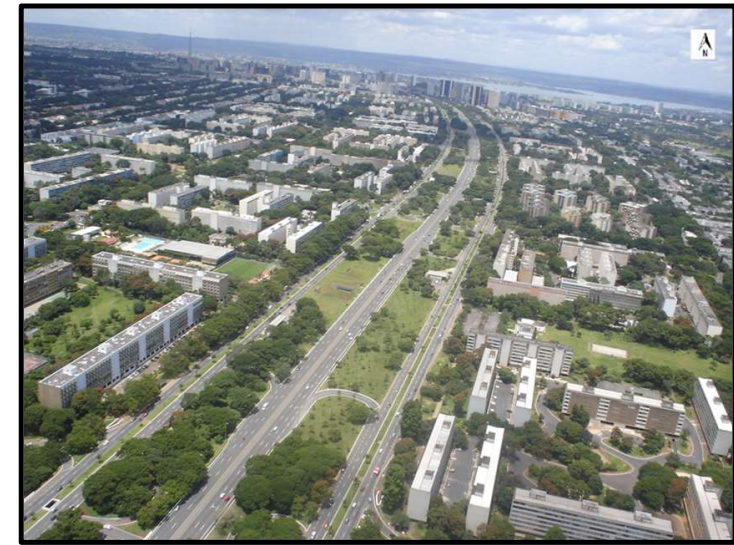

Figura 2: Imagem parcial do Eixo Rodoviário do Plano Piloto de Brasília (Distrito Federal, Brasil) e de seus canteiros laterais arborizados.

\section{Coleta de dados sobre a avifauna}

A amostragem de aves baseou-se no método de ponto fixo (RALPH et al., 1993; BIBBY et al., 2000), considerado o mais eficiente em dados de contagem (RALPH et al., 1993). O ponto fixo é um tipo de técnica em que o observador estaciona em pontos aleatórios ou pré-definidos e coleta os dados de aves por meio de observações (RALPH et al., 1993; BIBBY et al., 2000). Com esse método, é possível estudar mudanças de comunidades de aves, diferenças na composição da espécie entre habitats, riqueza e abundância (RALPH et al., 1993).

Neste estudo, a seleção de pontos foi gerada com o auxílio do aplicativo Google Earth, com distribuição em formato de zigue-zague, para representar a variação da vegetação e das estruturas construídas presente nos canteiros que ladeiam o Eixo Rodoviário do Plano Piloto de Brasília. Os pontos apresentam aproximadamente 400 m de distância, que resguarda a distância mínima recomendada de 250 m (RALPH et al., 1993). Selecionaram-se 32 pontos fixos de amostragem divididos em 16 pontos na Asa Sul e 16 pontos na Asa Norte do Plano Piloto de Brasília (Figura. 1). A sequência de visitação dos pontos fixos foi 
determinada por sorteio (PENA et al., 2017). A coleta de dados no campo foi iniciada 30 min após o nascer do sol e prolongado durante as primeiras três horas de luz do dia em dias ensolarados e sem ventos fortes (PENA et al., 2017). O tempo de permanência em cada ponto fixo foi de $10 \mathrm{~min}$ contínuos, quando apenas as aves observadas nesse período e em um raio de $50 \mathrm{~m}$ foram identificadas e registradas.

Para a amostragem das aves, foi usado um binóculo Sakura $8 \times 42 \mathrm{~mm}$. Fotografias digitais foram tiradas sempre que possível com uma câmara Fujifilm Finepix Hs20Erx. As espécies das aves avistadas foram identificadas e, quando não identificadas no local, suas características essenciais para identificação foram anotadas e comparadas com literatura especializada (SICK, 1997, GWYNNE et al., 2010). A nomenclatura e a taxonomia das espécies de aves seguiram Piacentini et al. (2015). Foram consideradas vocalizações somente nos casos em que o contato visual com o indivíduo foi impossível (SACCO et al., 2013). Os dados coletados foram categorizados em voar sobre as árvores $(>20 \mathrm{~m})$, voar entre as árvores $(<20 \mathrm{~m})$, pousar nas árvores, pousar no chão. Para evitar superestimava de abundância, aves de uma mesma espécie avistadas em um mesmo local durante o mesmo levantamento foram contabilizadas como indivíduos diferentes somente se passados mais de 5 min entre os eventos (RALPH et al., 1993). Contudo, quando constatada a existência de outro indivíduo da mesma espécie no ponto amostral, essa regra é ignorada (RALPH et al., 1993). Alguns comportamentos foram registrados e fotografados nos pontos, como exemplo, deteç̧ão de ninhos e forrageio. As espécies foram agrupadas por tipo de habitat, segundo Sick (1997), Bagno e Marinho-Filho (2001), Gwynne et al. (2010), Oliveira et al. (2011). Foram realizadas seis repetições por ponto amostral entre setembro de 2018 e setembro de 2019, totalizando 384 visitas aos 32 pontos fixos. O levantamento foi conduzido por um único observador.

\section{Análises de dados}

Foram quantificadas as frequências das espécies. Os dados obtidos foram tabulados e a suficiência amostral foi verificada por meio da curva de acumulação de espécies, determinada pela aleatorização de mil permutações (Figura 3). A diversidade da comunidade foi calculada por meio do índice de diversidade Shannon-Wiener (MARGURAN, 1988). Análises dos dados e cálculos foram realizados no programa R Core Team (2019) RStudio versão 3.6.1, através do pacote "Vegan" (OKSANEN et al.,2019).

\section{RESULTADOS}

A curva de acumulação de espécies se aproximou da assíntota ao se encontrarem 72 espécies nos primeiros 17 pontos fixos e a amostragem dos outros 15 pontos fixos acrescentou 14 espécies de aves à comunidade estudada. A área amostrada somou 40 ha de gramados arborizados ao longo do Eixo Rodoviário do Plano Piloto de Brasília (Eixão). Como era esperado, houve picos de abundância de algumas espécies e uma tendência da abundância de outras espécies caírem progressivamente ( $<50$ indivíduos) (Figura 4). A diversidade provavelmente está relacionada às características locais da vegetação nos pontos amostrais (Figura 5). Futuras análises poderão avaliar melhor como às características da vegetação influenciam a diversidade de aves ao longo do Eixão. 
No total, foram registrados 2.027 indivíduos distribuídos em 86 espécies, 36 famílias e 15 ordens, restando uma espécie não identificada (Tabela 1). As famílias mais representadas na área de estudo foram Tyrannidae (13 espécies), seguido de Thraupidae (12 espécies), ambas da ordem Passeriformes. As famílias de aves não Passeriformes mais representadas foram Psittacidae (6 espécies), Columbidae (5 espécies) e Trochilidae (5 espécies). Houve um predomínio em abundância das espécies Furnarius rufus (180 indivíduos), Columba livea (176 indivíduos), Brotogeris chiriri (162 indivíduos), Pitangus sulphuratus (153 indivíduos) e Mimus saturninus (152 indivíduos). Essas espécies registram os maiores picos de abundância na área de estudo e Columba livea, Pitangus sulphuratus e Brotogeris. chiriri foram as espécies mais frequentes (27 pontos amostrais cada uma), seguidas por Furnarius rufus (Gmelin, 1788), Eupetonema macroura e Mimus satuninus (26 pontos amostrais cada uma).

Quanto ao habitat de ocorrência, 47 espécies são típicas de Cerrado sentido restrito. Dentre as espécies de hábito florestal, 32 fazem uso também do Cerrado sentido restrito. Apenas duas espécies foram consideradas restritas de formações florestais: Galbula ruficauda e Myiodynastes maculatus. Ardea alba e Amazonetta brasiliensis usam ambientes aquáticos. Das 86 espécies identificadas, 63 frequentam ou são comuns em áreas urbanizadas e apenas três espécies identificadas são exóticas ao Brasil: Columba livia, Passer domesticus e Estrilda astrild.

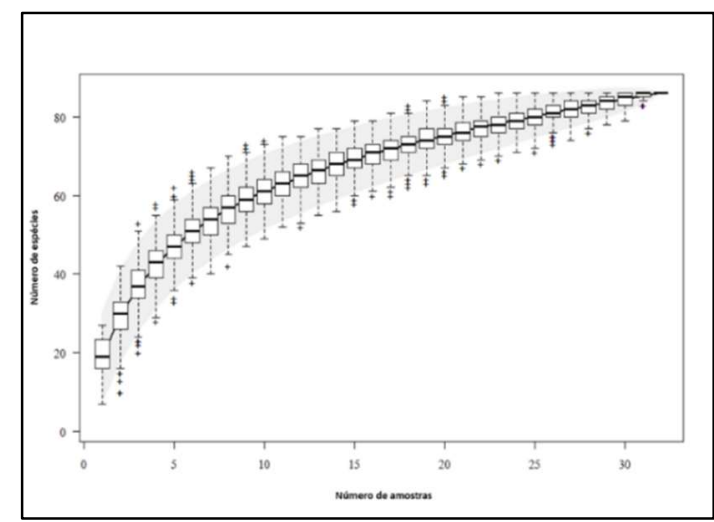

Figura 3: Curva de acumulação de espécies por randomização com 1000 permutações das amostras das espécies de aves do Eixão N/S. Em vertical os boxplot gerados a prtir dos valores desvio padrão e média.

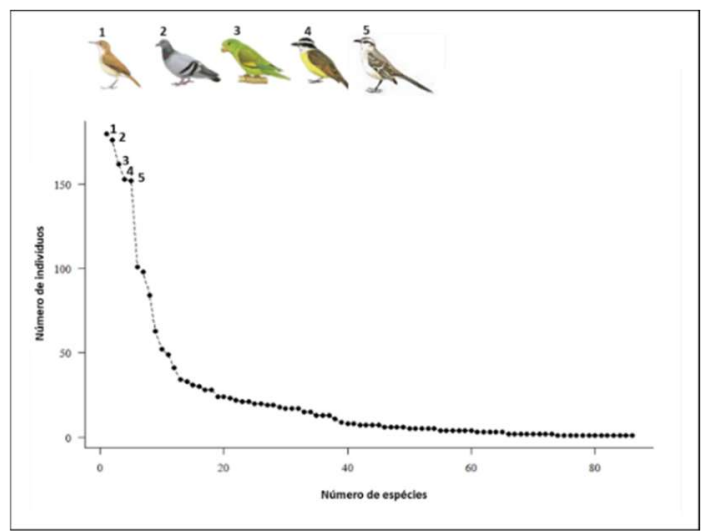

Figura 4: Rank da abundância demostrando que poucos foram as espécies com mais de 150 indivíduos. (1) Furnarius rufus,

(2) Columba livia, (3) Brotogeris chiriri, (3) Pitangus sulphuratus e (5) Mimus saturninus. Ilustrações das aves: Handbook of the Birds of the World Alive.

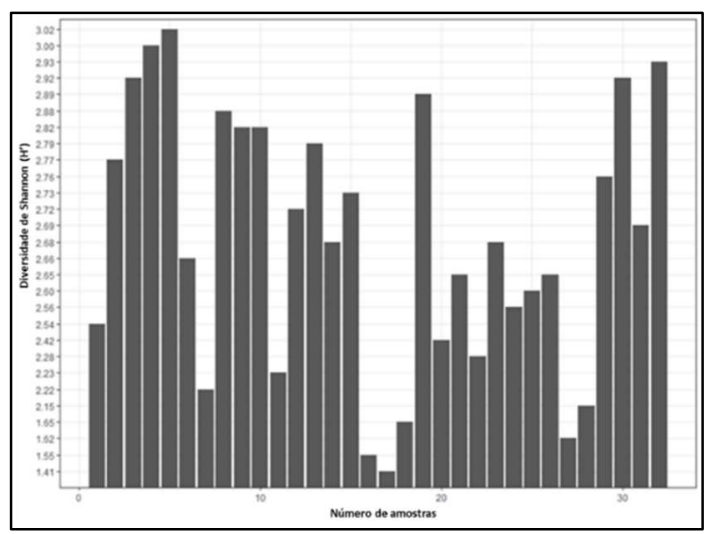

Figura 5: Índice de diversidade para o número de amostras. Os menores valores de diversidade estão próximos dos Centros urbanos (ponto 16,17 e 18). Os demais pontos com pouca diversidade estão mais próximos dos locais com maior número de veículos ou pessoas. 
Tabela 1: As aves que foram observadas nos canteiros do Eixão. Abundância é número total de indivíduos. Frequência é o número de pontos que as espécies ocorreram.

\begin{tabular}{|c|c|c|c|c|}
\hline \multicolumn{2}{|l|}{ Taxon } & \multirow[t]{2}{*}{ Abundância } & \multirow[t]{2}{*}{ Frequência } & \multirow[t]{2}{*}{ Habitat } \\
\hline ORDEM /Família /Espécie & Nome Popular & & & \\
\hline \multicolumn{5}{|l|}{ ANSERIFORMES } \\
\hline \multicolumn{5}{|l|}{ Anatidae } \\
\hline Amazonetta brasiliensis (GMELIN, 1789) & ananaí & 4 & 1 & $\mathrm{~A}$ \\
\hline \multicolumn{5}{|l|}{ PELECANIFORMES } \\
\hline \multicolumn{5}{|l|}{ Ardeidae } \\
\hline Ardea alba Linnaeus, 1758 & garça-branca & 3 & 2 & $\mathrm{~A}$ \\
\hline Syrigma sibilatrix (TEMMINCK, 1824) & maria-faceira & 2 & 1 & $\mathrm{C}$ \\
\hline \multicolumn{5}{|l|}{ Threskiornithidae } \\
\hline Theristicus caudatus (BODDAERT, 1783) & curicaca & 28 & 9 & ${ }^{*} \mathrm{C}$ \\
\hline \multicolumn{5}{|l|}{ CATHARTIFORMES } \\
\hline \multicolumn{5}{|l|}{ Cathartidae } \\
\hline Coragyps atratus (BECHSTEIN, 1793) & urubu & 7 & 2 & ${ }^{*} \mathrm{C}$ \\
\hline \multicolumn{5}{|l|}{ ACCIPITRIFORMES } \\
\hline \multicolumn{5}{|l|}{ Accipitridae } \\
\hline Elanus leucurus (VIEILLOT, 1818) & gavião-peneira & 1 & 1 & ${ }^{*} \mathrm{C}$ \\
\hline Rupornis magnirostris (GMELIN, 1788) & gavião-carijó & 4 & 2 & ${ }^{*} \mathrm{C}_{\mathrm{F}}$ \\
\hline \multicolumn{5}{|l|}{ CHARADRIIFORMES } \\
\hline \multicolumn{5}{|l|}{ Charadriidae } \\
\hline Vanellus chilensis (MOLINA, 1782) & quero-quero & 23 & 7 & ${ }^{*} \mathrm{C}$ \\
\hline \multicolumn{5}{|l|}{ COLUMBIFORMES } \\
\hline Columbidae & & & & \\
\hline Columbina talpacoti (TEMMINCK, 1810) & rolinha & 13 & 6 & ${ }^{*} \mathrm{C}_{\mathrm{F}}$ \\
\hline Columbina squammata (LESSON, 1831) & fogo-apagou & 17 & 10 & ${ }^{*} \mathrm{C}_{\mathrm{F}}$ \\
\hline Columba livia (GMELIN, 1789) & pombo-doméstico & 176 & 27 & $\mathrm{U}_{\mathrm{E}}$ \\
\hline Patagioenas picazuro (TEMMINCK, 1813) & asa-branca & 84 & 25 & ${ }^{*} \mathrm{C}_{\mathrm{F}}$ \\
\hline Zenaida auriculata (DES MURS, 1847) & avoante & 11 & 5 & $\mathrm{C}_{\mathrm{F}}$ \\
\hline CUCULIFORMES & & & & \\
\hline Cuculidae & & & & \\
\hline Piaya cayana (LINNAEUS, 1766) & alma-de-gato & 30 & 14 & ${ }^{*} \mathrm{~F}_{\mathrm{C}}$ \\
\hline Crotophaga ani (LINNAEUS, 1758) & anu-preto & 3 & 1 & ${ }^{*} \mathrm{C}_{\mathrm{F}}$ \\
\hline Guira guira (GMELIN, 1788) & anu-branco & 21 & 7 & ${ }^{*} \mathrm{C}_{\mathrm{F}}$ \\
\hline STRIGIFORMES & & & & \\
\hline Strigidae & & & & \\
\hline Glaucidium brasilianum (GMELIN, 1788) & caburé & 2 & 1 & $\mathrm{~F}_{\mathrm{C}}$ \\
\hline Athene cunicularia (MOLINA, 1782) & coruja-buraqueira & 19 & 4 & ${ }^{*} \mathrm{C}$ \\
\hline NYCTIBIIFORMES & & & & \\
\hline Nyctibiidae & & & & \\
\hline Nyctibius griseus (GMELIN, 1789) & urutau & 1 & 1 & $\mathrm{C}_{\mathrm{F}}$ \\
\hline APODIFORMES & & & & \\
\hline Apodidae & & & & \\
\hline Chaetura meridionalis (HELLMAYR, 1907) & andorinhão-do-temporal & 5 & 1 & ${ }^{*} \mathrm{C}_{\mathrm{F}}$ \\
\hline Trochilidae & & & & \\
\hline Phaethornis pretrei (LESSON \& DELATTRE, 1839) & rabo-branco-acanelado & 3 & 3 & $\mathrm{~F}_{\mathrm{C}}$ \\
\hline Eupetomena macroura (GMELIN, 1788) & beija-flor-tesoura & 98 & 26 & ${ }^{*} \mathrm{~F}_{\mathrm{C}}$ \\
\hline Chlorostilbon lucidus (SHAW, 1812) & besourinho-de-bico-vermelho & 6 & 6 & ${ }^{*} \mathrm{C}_{\mathrm{F}}$ \\
\hline Thalurania furcata (GMELIN, 1788) & beija-flor-tesoura-verde & 1 & 1 & $\mathrm{~F}_{\mathrm{C}}$ \\
\hline Amazilia fimbriata (GMELIN, 1788) & beija-flor-de-garganta-verde & 7 & 6 & ${ }^{*} \mathrm{C}_{\mathrm{F}}$ \\
\hline GALBULIFORMES & & & & \\
\hline Galbulidae & & & & \\
\hline Galbula ruficauda (CUVIER, 1816) & ariramba & 2 & 1 & $\mathrm{~F}$ \\
\hline PICIFORMES & & & & \\
\hline Ramphastidae & & & & \\
\hline Ramphastos toco (STATIUS MULLER, 1776) & tucanuçu & 1 & 1 & ${ }^{*} \mathrm{C}_{\mathrm{F}}$ \\
\hline Picidae & & & & \\
\hline Colaptes melanochloros (GMELIN, 1788) & pica-pau-verde-barrado & 24 & 14 & ${ }^{*} \mathrm{~F}_{\mathrm{C}}$ \\
\hline Colaptes campestris (VIEILLOT, 1818) & pica-pau-do-campo & 6 & 4 & ${ }^{*} \mathrm{C}_{\mathrm{F}}$ \\
\hline FALCONIFORMES & & & & \\
\hline Falconidae & & & & \\
\hline Caracara plancus (MILLER, 1777) & carcará & 34 & 11 & ${ }^{*} \mathrm{C}$ \\
\hline Falco sparverius LINNAEUS, 1758 & quiriquiri & 5 & 3 & $\mathrm{C}$ \\
\hline
\end{tabular}




\begin{tabular}{|c|c|c|c|c|}
\hline \multicolumn{5}{|l|}{ PSITTACIFORMES } \\
\hline \multicolumn{5}{|l|}{ Psittacidae } \\
\hline Diopsittaca nobilis (LINNAEUS, 1758) & maracanã-pequena & 5 & 2 & $* \mathrm{~F}_{\mathrm{C}}$ \\
\hline Psittacara leucophthalmus (STATIUS MULLER, 1776) & periquitão & 13 & 4 & ${ }^{*} \mathrm{C}_{\mathrm{F}}$ \\
\hline Eupsittula aurea (GMELIN, 1788) & periquito-rei & 6 & 2 & ${ }^{*} \mathrm{C}_{\mathrm{F}}$ \\
\hline Forpus xanthopterygius (SPIX, 1824) & tuim & 7 & 3 & $\mathrm{~F}_{\mathrm{C}}$ \\
\hline Brotogeris tirica (GMELIN, 1788) & periquito-verde & 2 & 1 & ${ }^{*} \mathrm{~F}_{\mathrm{C}}$ \\
\hline Brotogeris chiriri (VIEILLOT, 1818) & $\begin{array}{l}\text { periquito-de-encontro- } \\
\text { amarelo }\end{array}$ & 162 & 27 & ${ }^{*} \mathrm{~F}_{\mathrm{C}}$ \\
\hline \multicolumn{5}{|l|}{ PASSERIFORMES } \\
\hline \multicolumn{5}{|l|}{ Thamnophilidae } \\
\hline Taraba major (VIEILLOT, 1816) & choró-boi & 1 & 1 & $\mathrm{~F}_{\mathrm{C}}$ \\
\hline \multicolumn{5}{|l|}{ Dendrocolaptidae } \\
\hline Lepidocolaptes angustirostris (VIEILLOT, 1818) & arapaçu-de-cerrado & 9 & 6 & $\mathrm{C}_{\mathrm{F}}$ \\
\hline \multicolumn{5}{|l|}{ Furnariidae } \\
\hline Furnarius rufus (GMELIN, 1788) & joão-de-barro & 180 & 26 & ${ }^{*} \mathrm{C}_{\mathrm{F}}$ \\
\hline Phacellodomus rufifrons (WIED, 1821) & joão-de-pau & 1 & 1 & $C_{F}$ \\
\hline \multicolumn{5}{|l|}{ Rhynchocyclidae } \\
\hline Todirostrum cinereum (LINNAEUS, 1766) & ferreirinho-relógio & 17 & 9 & ${ }^{*} \mathrm{~F}_{\mathrm{C}}$ \\
\hline \multicolumn{5}{|l|}{ Tyrannidae } \\
\hline Camptostoma obsoletum (TEMMINCK, 1824) & risadinha & 20 & 10 & ${ }^{*} \mathrm{~F}_{\mathrm{C}}$ \\
\hline Elaenia flavogaster (THUNBERG, 1822) & guaracava-de-barriga-amarela & 22 & 10 & ${ }^{*} \mathrm{C}_{\mathrm{F}}$ \\
\hline Phyllomyias fasciatus (THUNBERG, 1822) & piolhinho & 2 & 1 & ${ }^{*} \mathrm{~F}_{\mathrm{C}}$ \\
\hline Pitangus sulphuratus (LINNAEUS, 1766) & bem-te-vi & 153 & 27 & ${ }^{*} \mathrm{~F}_{\mathrm{C}}$ \\
\hline Machetornis rixosa (VIEILLOT, 1819) & suiriri-cavaleiro & 17 & 10 & $* \mathrm{C}$ \\
\hline Myiodynastes maculatus (STATIUS MULLER, 1776) & bem-te-vi-rajado & 1 & 1 & $\mathrm{~F}$ \\
\hline Megarynchus pitangua (LINNAEUS, 1766) & neinei & 19 & 7 & ${ }^{*} \mathrm{~F}_{\mathrm{C}}$ \\
\hline Myiozetetes similis (SPIX, 1825) & $\begin{array}{l}\text { bentevizinho-de-penacho- } \\
\text { vermelho }\end{array}$ & 4 & 4 & ${ }^{*} \mathrm{~F}_{\mathrm{C}}$ \\
\hline Tyrannus melancholicus (VIEILLOT, 1819) & suiriri & 101 & 19 & ${ }^{*} \mathrm{C}_{\mathrm{F}}$ \\
\hline Tyrannus savana (DAUDIN, 1802) & tesourinha & 31 & 11 & ${ }^{*} \mathrm{C}_{\mathrm{F}}$ \\
\hline $\begin{array}{l}\text { Griseotyrannus aurantioatrocristatus (D'ORBIGNY et } \\
\text { al., 1837) }\end{array}$ & peitica-de-chapéu-preto & 3 & 2 & ${ }^{*} \mathrm{~F}_{\mathrm{C}}$ \\
\hline Empidonomus varius (VIEILLOT, 1818) & peitica & 4 & 4 & ${ }^{*} \mathrm{~F}_{\mathrm{C}}$ \\
\hline Xolmis cinereus (VIEILLOT, 1816) & primavera & 15 & 10 & $* \mathrm{C}$ \\
\hline \multicolumn{5}{|l|}{ Vireonidae } \\
\hline Cyclarhis gujanensis (GMELIN, 1789) & pitiguari & 21 & 14 & ${ }^{*} \mathrm{~F}_{\mathrm{C}}$ \\
\hline \multicolumn{5}{|l|}{ Hirundinidae } \\
\hline Pygochelidon cyanoleuca (VIEILLOT, 1817) & andorinha-pequena-de-casa & 63 & 9 & $* \mathrm{C}$ \\
\hline Stelgidopteryx ruficollis (VIEILLOT, 1817) & andorinha-serradora & 5 & 2 & $\mathrm{C}$ \\
\hline Progne chalybea (GMELIN, 1789) & andorinha-grande & 5 & 3 & ${ }^{*} \mathrm{C}_{\mathrm{F}}$ \\
\hline \multicolumn{5}{|l|}{ Troglodytidae } \\
\hline Troglodytes musculus (NAUMANN, 1823) & corruíra & 18 & 13 & ${ }^{*} \mathrm{C}_{\mathrm{F}}$ \\
\hline \multicolumn{5}{|l|}{ Polioptilidae } \\
\hline Polioptila dumicola (VIEILLOT, 1817) & balança-rabo-de-máscara & 7 & 4 & $*^{*} \mathrm{~F}_{\mathrm{C}}$ \\
\hline \multicolumn{5}{|l|}{ Turdidae } \\
\hline Turdus leucomelas (VIEILLOT, 1818) & sabiá-branco & 4 & 4 & $\mathrm{~F}_{\mathrm{C}}$ \\
\hline Turdus rufiventris (VIEILLOT, 1818) & sabiá-laranjeira & 49 & 19 & $* \mathrm{~F}_{\mathrm{C}}$ \\
\hline Turdus amaurochalinus (CABANIS, 1850) & sabiá-poca & 8 & 7 & ${ }^{*} \mathrm{~F}_{\mathrm{C}}$ \\
\hline \multicolumn{5}{|l|}{ Mimidae } \\
\hline Mimus saturninus (LICHTENSTEIN, 1823) & sabiá-do-campo & 152 & 26 & $* \mathrm{C}$ \\
\hline \multicolumn{5}{|l|}{ Passerellidae } \\
\hline Zonotrichia capensis (STATIUS MULLER, 1776) & tico-tico & 4 & 2 & $* \mathrm{C}$ \\
\hline \multicolumn{5}{|l|}{ Icteridae } \\
\hline Icterus pyrrhopterus (VIEILLOT, 1819) & encontro; & 24 & 14 & ${ }^{*} \mathrm{~F}_{\mathrm{C}}$ \\
\hline Gnorimopsar chopi (VIEILLOT, 1819) & pássaro-preto & 8 & 5 & C \\
\hline Molothrus bonariensis (GMELIN, 1789) & chupim & 52 & 12 & $* \mathrm{C}$ \\
\hline Thraupidae & & & & \\
\hline Tangara sayaca (LINNAEUS, 1766) & sanhaço-cinzento & 33 & 15 & ${ }^{*} \mathrm{C}_{\mathrm{F}}$ \\
\hline Tangara palmarum (WIED, 1821) & sanhaço-do-coqueiro & 1 & 1 & $*^{*} \mathrm{~F}_{\mathrm{C}}$ \\
\hline Tangara cayana (LINNAEUS, 1766) & saíra-amarela & 13 & 7 & ${ }^{*} \mathrm{C}_{\mathrm{F}}$ \\
\hline Nemosia pileata (BODDAERT, 1783) & saíra-de-chapéu-preto & 20 & 8 & ${ }^{*} \mathrm{C}_{\mathrm{F}}$ \\
\hline Sicalis flaveola (LINNAEUS, 1766) & canário-da-terra & 28 & 7 & $\mathrm{~F}_{\mathrm{C}}$ \\
\hline Volatinia jacarina (LINNAEUS, 1766) & tiziu & 2 & 1 & $* \mathrm{C}$ \\
\hline
\end{tabular}




\begin{tabular}{|l|l|l|l|l|}
\hline Tersina viridis (ILLIGER, 1811) & saí-andorinha & 6 & 3 & $\mathrm{~F}_{\mathrm{C}}$ \\
\hline Dacnis cayana (LINNAEUS, 1766) & saí-azul & 1 & 1 & ${ }^{*} \mathrm{~F}_{\mathrm{C}}$ \\
\hline Coereba flaveola (LINNAEUS, 1758) & cambacica & 15 & 9 & ${ }^{*} \mathrm{~F}_{\mathrm{C}}$ \\
\hline Sporophila lineola (LINNAEUS, 1758) & bigodinho & 3 & 1 & ${ }^{*} \mathrm{C}$ \\
\hline Sporophila nigricollis (VIEILLOT, 1823) & baiano & 1 & 1 & ${ }^{*} \mathrm{C}$ \\
\hline Sporophila caerulescens (VIEILLOT, 1823) & coleirinho & 2 & 1 & ${ }^{*} \mathrm{C}$ \\
\hline Fringillidae & & & & \\
\hline Euphonia chlorotica (LINNAEUS, 1766) & fim-fim & 1 & 1 & ${ }^{*} \mathrm{~F}_{\mathrm{C}}$ \\
\hline Euphonia violacea (LINNAEUS, 1758) & gaturamo & 1 & 1 & ${ }^{*} \mathrm{~F}_{\mathrm{C}}$ \\
\hline Estrildidae & & & & \\
\hline Estrilda astrild (LINNAEUS, 1758) & bico-de-lacre & 2 & 1 & \\
\hline Passeridae & & & & \\
\hline Passer domesticus (LINNAEUS, 1758) & pardal & 1 & 13 & \\
\hline Não-identificado & - & & 1 & \\
\hline & & & \\
\hline
\end{tabular}

(A) espécies aquáticas que habitam rios, lagos, brejos e ambientes alagáveis; (C) espécie restrita de ambiente campestre (cerrado stricto senso) e áreas abertas; $\left(C_{F}\right)$ espécies de ambiente campestre e áreas abertas, mas que usam formações florestais; $(F)$ espécie restrita de formações florestais; $\left(F_{C}\right)$ espécies de formações florestais, mas que usam de habitats campestres e áreas abertas; (U) espécie adaptada ao ambiente urbano e (E) espécie exótica. (*) espécies comuns ou com razoável ocorrência; em cidade com árvores esparsas ou aglomeradas (jardins, pomares, praças e áreas residenciais arborizadas).

\section{DISCUSSÃO}

Registou-se abundância e frequência de espécies que suportam melhor as limitações da urbanização. Principalmente, nos locais que arborizados ao longo do Eixão. Foram contabilizadas 86 espécies de aves ao longo do Eixão, o que representa 19\% das espécies de aves registradas no Distrito Federal (FARIA, 2008) ao longo de uma via com intenso tráfego de veículos. Urbanização e aglomerações humanas reduzem a riqueza e a abundância de aves (ORTEGA-ÁLVAREZ et al., 2011; FONTANA et al., 2011), sobretudo próximo a vias com um fluxo elevado de veículos (MORELLI et al., 2014). O tráfego de veículos aumenta a mortalidade de aves por colisão e a poluição sonora as expulsa da área (FORMAN et al., 1998; FORMAN et al., 2002). Entretanto, diferentes características de ruas e avenidas são capazes de reduzir os efeitos de distúrbios, como poluição sonora e do ar (MORELLI et al., 2014). Ruas arborizadas são efetivas em fornecer passagem para aves, exercendo papel semelhante ao dos corredores ecológicos, locais de pouso, forrageamento e nidificação (FERNÁNDEZ-JURICIC, 2000). Dessa forma, o Eixão pode ser capaz de abrigar uma elevada diversidade de aves em seus canteiros arborizados

A infraestrutura verde influencia a ocupação e distribuição das aves no ambiente urbano. Especificamente, os recursos fornecidos pela vegetação de variados hábitos (CLERGEAU et al., 2006; TOLEDO et al., 2012), a presença de árvores adultas e de grande porte (BARTH, 2015; FERNÁNDEZ-JURICIC, 2000), a riqueza de árvores nativas (PENA et al., 2017) e exóticas (IKIN et al., 2013) e proporção de área verde na malha urbana (KANG et al., 2015) influenciam a riqueza e diversidade de aves em cidades (DALE, 2018). A presença de parques com fragmentos de ecossistemas em bom estado de conservação (FERNÁNDEZ-JURICIC, 2000) facilita a conectividade entre paisagens preservadas e áreas urbanas e incrementa a diversidade de aves nas cidades (GRAFIUS et al., 2017). A arborização ao longo de todo o Eixão, espécies arbóreas ornitocóricas, recursos florísticos, locais para nidificação, presença de árvores adultas e presença de parques próximos que podem ter servido de apoio para comunidade de aves encontrada.

O Cerrado brasileiro consiste de um mosaico de fitofisionomias que confere grande heterogeneidade à paisagem, o que contribui para a elevada riqueza e diversidade de aves (SOUZA et al., 2019). Em ambientes 
urbanos, a heterogeneidade criada pela combinação entre áreas verdes e a áreas construídas é fundamental para criar oportunidades para diferentes espécies de aves no meio urbano (REIS et al., 2012; SOUZA et al., 2019). Os canteiros arborizados deste estudo ladeiam em suas partes internas a principal via que cruza toda a extensão da escala residencial de Brasília. Em suas partes externas, os mesmos canteiros emolduram os prédios residenciais dessa escala, que também é internamente arborizada (LIMA et al., 2010). Esse arranjo cria bosques interligados e contribuiu para criar ambientes propícios à manutenção de fauna na área urbana, já que nos maciços arborizados há abrigo, alimento, estruturas para nidificação e trânsito entre áreas verdes (BARTH et al., 2015; MELLES et al., 2003; RODRIGUES et al., 2018; SACCO et al., 2013). Em estudo realizado em outra cidade do Cerrado brasileiro (Palmas, Tocantins), Reis et al. (2012) observaram correlação positiva entre a presença de áreas residenciais e arborização de médio porte com a avifauna urbana. Nesse sentido, algumas espécies de aves podem ser favorecidas pela associação de árvores com áreas construídas (EVANS et al., 2009). É possível que as espécies mais abundantes do Eixão foram favorecidas pela heterogeneidade da paisagem.

As espécies de aves mais abundantes deste estudo são consideradas muito tolerantes à urbanização (ABILHOA et al., 2017). F. rufus, C. livea, B. chiriri, P. sulphuratus. Sabe-se que as aves urbanas tolerantes tendem aumentar sua abundância (BLAIR, 1996). Uma possível explicação é que áreas urbanas atuam como filtros na seleção de espécies da fauna que se adaptam ás cidades (EVANS et al., 2009). Esse fenômeno resulta no aumento da coexistência de táxons filogeneticamente e funcionalmente similares (SOL et al., 2017; CALLAGHAN et al., 2019). Traços taxonômicos e o nível de tolerância explicam os fatores que determinam a existência e abundância de animais no meio urbano (SOL et al., 2013). Nichos amplos e estratégias alimentares menos especializadas são essenciais para se adaptar e persistir no meio urbano (CROCl et al., 2008; CALLAGHAN et al., 2019).

Os Passeriformes são um clado rico em espécies em todo mundo (RICKLEFS, 2012). Seu sucesso de sobrevivência e adaptação em ambientes perturbados reside na capacidade de ocupar diferentes (RICKLEFS, 2012). F. rufus e M. Saturninus são exemplos de espécies que usaram os recursos na área deste estudo de diferentes maneiras. F. rufus é uma espécie favorecida pelo desmatamento brasileiro, que coloniza locais diversos de sua distribuição original (SICK, 1997). Essa espécie, que é considerada tolerante ao meio urbano (ABILHOA et al., 2017), foi a mais abundante e uma das mais frequentes nos pontos de amostragem deste estudo. A distribuição geográfica $F$. rufus pode estar associada ao hábito de se produzir uma mistura de lama e capim para construção de ninhos (SHIBUIYA et al., 2015). Lama e capim são facilmente encontrados em áreas urbanas e em processo de urbanização. Neste estudo, observou-se que $F$. rufus construiu ninhos ao longo dos canteiros arborizados. M. saturninus apesar de não ser tolerante ao meio urbano (ABILHOA e AMORIN, 2017), possui sucesso reprodutivo em vários habitats. Ela é considerada comum em áreas abertas, com arbustos isolados do Cerrado e em cidades (SICK, 1997). M. saturninus não foi a espécie mais abundante e frequente, mas é comum na área residencial do Plano Piloto de Brasília (OLIVEIRA et al., 2011).

Entre os Passeriformes, a família mais rica foi Tyrannidae, maior família de aves no Brasil (PIACENTINI et al., 2015). Essa família é conhecida por ser insetívora/onívora, possuir diversas técnicas de forrageamento 
(MARTINS-OLIVEIRA et al., 2012) e habitar uma variedade de ambientes, desde densas florestas tropicais até pastagens (BURNS et al., 2014). P. sulphuratus, por exemplo, é adaptado aos ambientes urbanos brasileiros (SICK, 1997) e neste estudo foi a espécie mais frequente nos pontos amostrais. Trata-se de uma espécie de ave generalista, capaz de explorar diversos recursos disponíveis nas cidades o que facilita seu sucesso em se estabelecer em ambientes urbanos (MARTINS-OLIVEIRA et al., 2012) (Figura 6). Todavia, como sua distribuição é incerta e ela não sofre influencias de fatores sazonais ou locais, essa espécie não é considerada uma boa indicadora ambiental (AMÂNCIO et al., 2008). Thraupidae é a segunda maior família de aves nas regiões neotropicais. Tiranídeos são comuns em paisagens urbanas brasileiras em diferentes regiões do país (FONTANA et al., 2011; REIS et al., 2012). São capazes de ocupar diferentes ambientes, como parques urbanos, praças, jardins (GALINA et al., 2006; BRAGA et al., 2010, PERILLO et al., 2017) e ruas com distintas características locais da arborização (PENA et al., 2017).

Outras ordens ocorreram na área de estudo, como os Psittacidae. Em nível global, essa ordem possui menos espécies exploradoras do meio urbano do que as outras famílias mencionadas (SOL et al., 2017). No Brasil, existem inúmeras espécies que respondem de maneira diferente a alterações (SICK, 1997; MARQUES et al., 2018). Algumas espécies são pouco exigentes para habitat, menos sensíveis à urbanização e com diferentes estratégias de forrageamento (SICK, 1997; MARQUES et al., 2018). B. chiriri segue esse exemplo e foi uma das espécies mais abundantes e frequentes em todos os pontos amostrais. $\mathrm{O}$ grande número de árvores frutíferas deve ter atraído as aves até os canteiros, porque $B$. chiriri usa várias fontes de frutos e alimentos quando necessário (SOUZA et al., 2019) (Figura 6). As famílias Trochillidae e Columbidae possuem muitos representantes em áreas urbanas (SOL et al., 2017). No Brasil, a família Trochillidae possui ampla distribuição geográfica (SICK, 1997) e na matriz urbana, aves dessa família associam-se à disponibilidade de recurso floral não-ornitofílico (MENDONÇA et al., 2005), sobretudo no inverno, quando espécies migram para áreas floridas (NEGRET, 1988). Observou-se neste estudo que E. macroura visitou diferentes espécies de árvores dos gêneros Handroanthus, Tabebuia e Ceiba plantadas ao longo dos canteiros do Eixão (Figura 6).

A família Columbidae é conhecida por possuir muitas espécies tolerantes ao meio urbano (SOL et al., 2017). C. livia, por exemplo, foi a espécie mais frequente em todos os pontos amostrais. Contudo, a abundância dessa espécie se concentrou nos sítios próximos a áreas comerciais e com maior densidade humana. Neste estudo não foi constado o uso de recursos arbóreos por $C$. livia, espécie exótica ao continente americano (SICK, 1997). P. domesticus e E. astrild, igualmente exótico nas américas (SICK, 1997), foram pouco frequentes e pouco abundantes nos canteiros da área de estudo, apesar de serem muito associados a ambientes urbanos ou a pastagens (CASE et al., 1996; SICK, 1997). Estudos tem demostrados baixas frequência e abundância de $P$. domesticus em regiões mais arborizadas das cidades (MACGREGOR et al., 2012). P. domesticus e E. astrild foram capazes de usar a paisagem urbana de Brasília e pareceram responder positivamente à urbanização. Elas são espécies generalistas muito atraídas para locais com maior disponibilidade de alguns alimentos humanos e terrenos baldios nas cidades (EVANS et al., 2009; MACGREGOR et al., 2012). Além disso, a menor complexidade estrutural das cidades beneficia espécies menos exigentes em detrimento de espécies especialistas (ORTEGA-ALVAREZ et al., 2011). A diversidade de 
aves nas cidades diminui na medida em que o nível de urbanização se acentua (CROCl et al., 2008; CHACE et al., 2006; ORTEGA-ALVAREZ et al., 2011). Espécies adaptadas às estruturas artificiais dos centros urbanos e aos recursos alimentares humanos se beneficiam e dominam o ambiente, como C. Lívia (MACGREGOR et al., 2012).

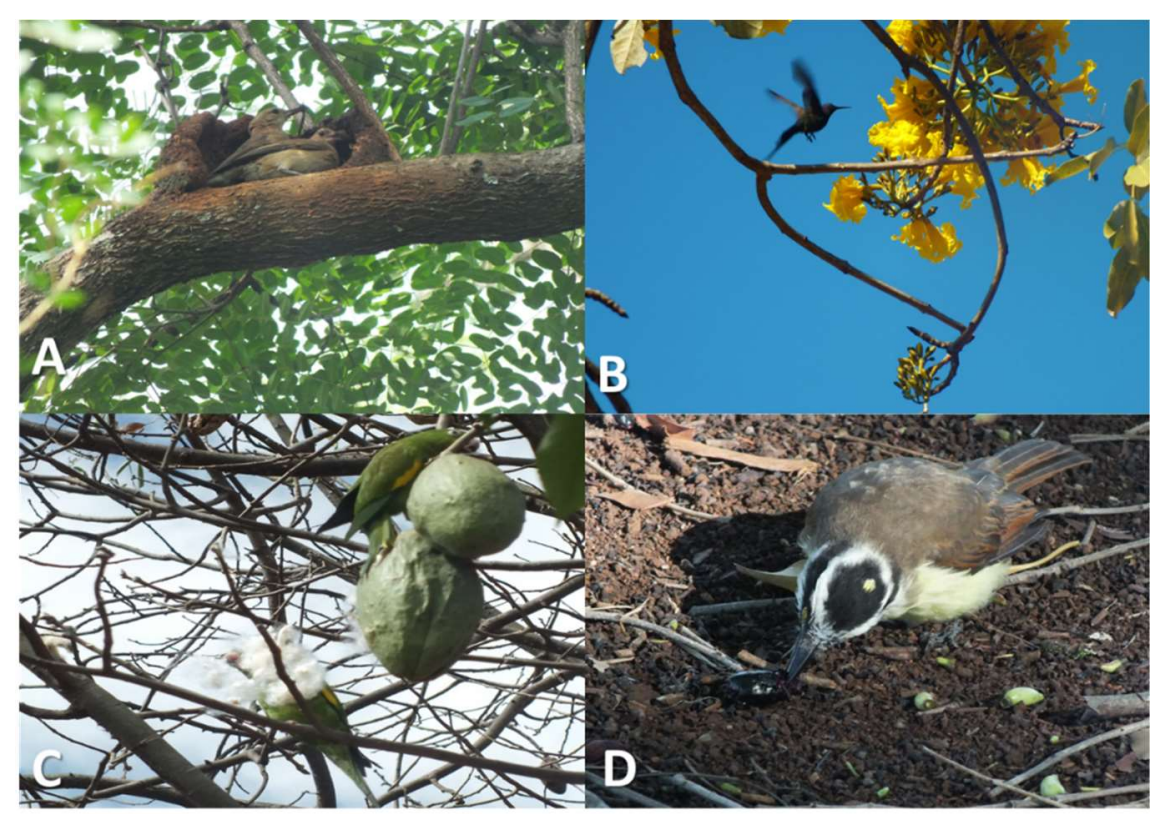

Figura 6: Uma rua urbana tem diversas limitações, mas foram atrativos para muitas espécies de aves. Entre elas: (A) Furnarius rufus construindo ninho; (B) As flores de Tabebuia sp. sendo atrativo para Eupetonema macroura na época de inverno; (C) Brotogeris chiriri alimentando de frutos de Ceiba speciosa uma espécie de dispersão anemocórica

(ALENCAR, 2008); (D) E Syzygium cumini uma árvore exótica (LIMA et al., 2010), mas que serviu de alimento para Pitangus sulphuratus.

As aves nativas amostradas neste estudo são espécies de áreas campestres e abertas, mas que usam também ecossistemas florestais. O bioma Cerrado apresenta quatorze fitofisionomias distribuídas em formações campestres, savânicas e florestais (RIBEIRO et al., 1998). Características da vegetação influenciam a presença de aves, pois algumas são restritas a determinadas formações fitofisionômicas (BAGNO e MARINHO-FILHO, 2001). Algumas aves nativas do Cerrado realizam rotatividade diária entre áreas mais densa e áreas abertas (CAVALCANTI, 1999) como estratégia para maximizar a obtenção de recursos (TUBELIS et al., 2001). Essa estratégia favorece a riqueza de espécies em áreas campestres, bordas de matas e áreas abertas (JESUS et al., 2018). Muitas aves não têm restrições de deslocamento entre fragmentos de vegetação preservados e áreas fragmentadas (JESUS et al., 2018).

A expansão urbana e da agricultura no Distrito Federal concentra-se em áreas campestres (CAVALCANTI, 1999), deslocando a avifauna típica dessa formação. Os dados encontrados neste estudo sugerem que a maioria das aves são de origem campestre e generalistas. Portanto, canteiros lineares ao longo de ruas ou rodovias são efetivos em fornecer passagem para aves, exercendo papel semelhante ao dos corredores ecológicos (FERNÁNDEZ-JURICIC, 2000; MATSUBA et al., 2016). Os canteiros arborizados do Eixo Rodoviário do Plano Piloto de Brasília foram considerados corredores ecológicos em estudo anterior (CORRÊA et al., 2006) e eles dão suporte à presença de algumas espécies de aves na parte central da cidade. Apesar da presença de 86 espécies identificadas neste estudo (Tabela 1), não se encontrou espécie endêmica do Cerrado na área urbana estudada (GWYNNE et al., 2010; OLIVEIRA et al., 2011). O corredor verde (CORRÊA 
et al., 2006), representado pelos canteiros arborizados deste estudo, não apresentou condições ecológicas suficientes para dar suporte a espécies de aves especialistas, fato comum em ambientes urbanos arborizados (BLAIR, 1996; CAVALCANTI, 1999).

Algumas espécies mais sensíveis foram amostradas na área de estudo. Como exemplo, Nyctibius griseus, Thalurania furcata, Taraba major, Phacellodomus rufifrons (Tabela1) habitam bordas de matas ou árvores em áreas abertas (SICK, 1997) e não são comuns em cidades (GWYNNE et al., 2010). Gálbula ruficauda e Myiodynastes maculatus se associam a ambientes florestais e também não costumam ocorrer em cidades (GWYNNE et al., 2010). Outras espécies, como Myiodynastes maculatus, Tyrannus melancholicus, Tyrannus savanna, Empidonomus varius e Griseotyrannus aurantioatrocristatus, migram na primavera e aumentam a diversidade de aves no Distrito Federal em setembro e outubro (NEGRET, 1988). Nesse caso, recursos nas cidades para aves migratórias podem existir na infraestrutura verde (EVANS et al., 2011). Ardea alba e Amazonetta brasiliensis são espécies aquáticas, e o suporte dado pelo Lago Paranoá, que emoldura o Plano Piloto de Brasília, demanda estudo. Assim, o Eixão é capaz de abrigar uma grande diversidade de aves provindas de áreas naturais adjacentes ou migrantes, servindo de suporte para sobrevivência de algumas espécies que buscam recursos em ambientes urbanos. Por isso, na falta de habitats nativas diferentes espécies vegetais urbanas podem fornecer recursos diversificados e servir de proteção para aves, por exemplo, com dieta mais diversas para onívoros e várias oportunidades de nidificação (MURGUI, 2007).

As cidades precisam de infraestrutura verde para conectar habitats nativos e assim mitigar os efeitos negativos da urbanização (KANG et al., 2015). Estudos sobre aves no meio urbano são importantes, porque ainda é obscuro o efeito da urbanização sobre a riqueza de aves (REIS et al., 2012). É preciso compreender os novos padrões ambientais diante da acelerada transformação das cidades (GRIMM et al., 2008). Atividades de planejamento e gestão urbana podem ser implementadas com base em uma composição diversificada de árvores nativas (CORRÊA et al., 2015), que contribuiriam para resgatar a natureza nas cidades (SOUZA et al., 2019).

\section{CONCLUSÕES}

Os resultados obtidos reforçam a proposta que a diversidade da avifauna esteja diretamente relacionada à vegetação dos canteiros do Eixão. As aves generalistas e oportunistas encontradas neste estudo podem frequentemente, ser encontradas em áreas urbanas, mas espécies especialistas e restritas vivem em ambientes preservados. Essa característica é um padrão em várias partes do mundo (CALLAGHAN et al., 2019). Como já era esperado, abundância de algumas espécies foram mais pronunciadas em detrimento de outras. As aves encontradas apresentam em sua maioria habitat de origem campestre e abertas. Na necessidade de obtenção de recursos usam ecossistemas florestais. Todavia, na falta de habitats preservados algumas usam recursos da arborização urbana. Os canteiros do Eixão ofereceram locais de pouso, descanso, recursos alimentares e ambientes para reprodução. A heterogeneidade da paisagem pode contribuído para a riqueza de aves encontrada (SOUZA et al., 2018). Como exemplo, áreas residenciais próximas dos canteiros do Eixão. 
Neste estudo, uma rua arborizada abrigou uma rica quantidade de aves, mas apenas espécies que suportam as limitações da urbanização. A abundância e frequência foi observada por espécies generalistas e provindas de áreas campestres e abertas. Neste sentido, os canteiros arborizados têm uma importância para avifauna, constituindo um refúgio nesses ambientes muito antrópicos. Em geral, as mesmas aves generalistas foram registradas em locais similares, pois a vegetação da rua, os veículos e a disponibilidade de alimento eram semelhantes. Isto demostra a necessidade de um manejo mais adequado dos canteiros de ruas, visando oferecer condições favoráveis para sustentação de diferentes espécies de aves.

AGRADECIMENTOS: Ao Programa de Pós-Graduação em Ciências Ambientais (PPGCA) da Universidade de Brasília pela oportunidade de realização desta pesquisa.

\section{REFERÊNCIAS}

ABILHOA, V.; AMORIN, R.. Effects of urbanization on the avian community in a southern Brazilian city. Revista Brasileira de Ornitologia, v.25, n.1, p.31-39, 2017.

ALENCAR, F. O. C. C.. Arborização Urbana no Distrito Federal: história e espécies do cerrado. Brasília: Novacap, 2008.

AMÂNCIO, S.; SOUZA, V. B.; MELO, C.. Columba livia e Pitangus sulphuratus como indicadoras de qualidade ambiental em área urbana. Revista Brasileira de Ornitologia, v.16, n.1, p.32-37, 2008.

ARONSON, M. F. J.; LA SORTE, F. A.; NILON, C. H.; KATTI, M.; GODDARD, M. A.; LEPCZYK, C. A.; WARREN, P. S.; WILLIAMS, N. S. G.; CILLIERS, S.; CLARKSON, B.; DOBBS, C.; DOLAN, R.; HEDBLOM, M. S.; KLOTZ; KOOIJMANS, J. L.; KUHN, I. I. M.-F.; MCDONNELL, M.; MORTBERG, U.; PYSEK, P.; SIEBERT, S.; SUSHINSKY, J.; WERNER, P.; WINTER, M. A.. global analysis of the impacts of urbanization on bird and plant diversity reveals key anthropogenic drivers. Proceedings of the Royal Society B: Biological Sciences, v.281, n.1780, p.2014. DOI: http://doi.org/10.1098/rspb.2013.3330

BAGNO, M. A.; MARINHO-FILHO, J. A.. avifauna do Distrito Federal: uso de ambientes abertos e florestais e ameaças. In: RIBEIRO, J. F.; FONSECA, C. E. L.; SOUSA-SILVA, J. C.. Cerrado: caracterização e recuperação de matas de galeria. Planaltina: Embrapa Cerrados, 2001. p.495-528.

BARTH, B. J.; FITZGIBBON, S. I.; WILSON, R. S.. New urban developments that retain more remnant trees have greater bird diversity. Landscape and Urban Planning, v.136, p.122129, 2015. DOI:

http://doi.org/10.1016/j.landurbplan.2014.11.003

BIBBY, C. J.; BURGESS, N. D.; HILL, D. A.; MUSTOE, S. H.. Birds Census Techniques, Ecoscope Applied Ecologists. 2 ed. 2000.

BLAIR, R. B.. Land use and avian species diversity along an urban gradient. Ecological Applications, v.6, n.2, p.506-519, 1996.

BRAGA, T.; ZANZINI, A.; CERBONCINI, R.; MIGUEL, M.; MOURA, A.. Avifauna em praças da cidade de Lavras (MG): riqueza, similaridade e influência de variáveis do ambiente urbano. Revista Brasileira de Ornitologia, v.18, n.1, p.26-33, 2010.

BURNS, K. J.; SHULTZ, A. J.; TITLE, P. O.; MASON, N. A.; BARKER, F. K.; KLICK, J.; LANYON, S. M.; LOVETTE, I. J. Phylogenetics and diversification of tanagers (Passeriformes: Thraupidae), the largest radiation of Neotropical songbirds. Molecular Phylogenetics and Evolution, v.75, n.1, p.41-77, 2014. DOI: http://doi.org/10.1016/i.ympev.2014.02.006

CALLAGHAN, C. T.; BINO, G.; MAJOR, R. E.; MARTIN, J. M.; LYONS, M. B.; KINGSFORD, R. T.. Heterogeneous urban green areas are bird diversity hotspots: insights using continental-scale citizen science data. Landscape Ecology, v.34, n.6, p.1231-1246, 2019. DOI: http://doi.org/10.1007/s10980-019-00851-6

CASE, T. J.. Global patterns in the establishment and distribution of exotic birds. Biological Conservation, v.78, n.1-2, p.69-96, 1996. DOI: http://doi.org/10.1016/00063207(96)00019-5

CAVALCANTI, R. B.; SILVA, J. M. C.. Distrito Federal. In: VALENTE, R. M.. Conservação de Aves Migratórias Neárticas no Brasil. Belém: Conservação Internacional, 2011. p.400.

CAVALCANTI, R. B.. Bird species richness and conservation in the Cerrado region of central Brazil. Studies in Avian Biology, n.19, p.244-249, 1999.

CHACE, J. F.; WALSH, J. J.. Urban effects on native avifauna: A review. Landscape and Urban Planning, v.74, n.1, p.46-69, 2006. DOI:

http://doi.org/10.1016/j.landurbplan.2004.08.007

CLERGEAU, P.; CROCI, S.; JOKIMÄKI, J. KAISANLAHTIJOKIMÄKI, M. L.; DINETTI, M.. Avifauna homogenisation by urbanisation: Analysis at different European latitudes. Biological Conservation, v.127, n.3, p.336-344, 2006. DOI: http://doi.org/10.1016/j.biocon.2005.06.035

CORRÊA, R. S.; CARDOSO, E. S.; BAPTISTA, G. M. M.; MÉLO FILHO, B.. Zoneamento do território paraa identificação de corredores ecológicos no Distrito Federal. Geografia, v.31, n.1, p.137-149, 2006. 
CORRÊA, R. S.; MÉLO FILHO, B.; PINHEIRO, C. Q.; SANTOS, P. F.. Composição Florística Lenhosa De Jazidas Revegetadas No Distrito Federal. Biosci. J., v.31, n.3, p.908-922, 2015. DOI: http://doi.org/10.14393/BJ-v31n3a2015-22986

CROCI, S.; BUTET, A.; CLERGEAU, P.. Does Urbanization Filter Birds on the Basis of Their Biological Traits?. The Condor, v.110, n.2, p.223-240, 2008. DOI:

http://doi.org/10.1525/cond.2008.8409

DALE, S.. Urban bird community composition influenced by size of urban green spaces, presence of native forest, and urbanization. Urban Ecosystems, v.21, n.1, p.1-14, 2018. DOI: $\underline{\text { http://doi.org/10.1007/s11252-017-0706-x }}$

ESTEVO, C. A.; NAGY-REIS, M. B.; SILVA, W. R.. Urban parks can maintain minimal resilience for Neotropical bird communities. Urban Forestry and Urban Greening, v.27, n.2016, p.84-89, 2017. DOI:

http://doi.org/10.1016/j.ufug.2017.06.013

EVANS, K. L.; CHAMBERLAIN, D. E.; HATCHWELL, B. J.; GREGORY, R. D.; GASTON, K. J.. What makes an urban bird?. Global Change Biology, v.17, n.1, p.32-44, 2011. DOI: http://doi.org/10.1111/j.1365-2486.2010.02247.x

EVANS, K. L.; NEWSON, S. E.; GASTON, K. J.. Habitat influences on urban avian assemblages. Ibis, v.151, n.1, p.1939, 2009. DOI: http://doi.org/10.1111/i.1474919X.2008.00898.x

FARIA, I. P.. Novas ocorrências e registros relevantes de aves no Distrito Federal, Brasil, com comentários sobre distribuição local. Revista Brasileira de Ornitologia, v.16, n.1, p.40-43, 2008.

FERNÁNDEZ-JURICIC, E.. Avifaunal use of wooded streets in an urban landscape. Conservation Biology, v.14, n.2, p.513521, 2000. DOI: http://doi.org/10.1046/j.15231739.2000.98600.x

FONTANA, C. S.; BURGER, M. I.; MAGNUSSON, W. E.. Bird diversity in a subtropical South-American City: Effects of noise levels, arborisation and human population density. Urban Ecosystems, v.14, n.3, p.341-360, 2011. DOI: http://doi.org/10.1007/s11252-011-0156-9

FORMAN, R. T. T.; ALEXANDER, L. E.. Roads and their major ecological effects. Annual Review of Ecology and Systematics, v.29, p.207-231, 1998. DOI: http://doi.org/10.1146/annurev.ecolsys.29.1.207

FORMAN, R. T. T.; REINEKING, B.; HERSPERGER, A. M.. Road traffic and nearby grassland bird patterns in a suburbanizing landscape. Environmental Management, v.29, n.6, p.782800, 2002. DOI: http://doi.org/10.1007/s00267-001-0065-4

GALINA, A. B.; GIMENES, M. R.. Riqueza, composição e distribuição espacial da comunidade de aves em um fragmento florestal urbano em Maringá, Norte do Estado do Paraná, Brasil. Acta Scientiarum - Biological Sciences, v.28, n.4, p.379-388, 2006.

GRAFIUS, D. R.; CORSTANJE, R.; SIRIWARDENA, G. M.; PLUMMER, K. E.; HARRIS, J. A.. A bird's eye view: using circuit theory to study urban landscape connectivity for birds. Landscape Ecology, v.32, n.9, p.1771-1787, 2017. DOI: http://doi.org/10.1007/s10980-017-0548-1

GRIMM, N. B.; FAETH, S. H.; GOLUBIEWSKI, N. E.; REDMAN, C. L.; WU, J.; BAI, X.; BRIGGS, J. M.. Global change and the ecology of cities. Science, v.319, n.5864, p.756-760, 2008. DOI: http://doi.org/10.1126/science.1150195

GWYNNE, J. A.; RIDGELY, R. S.; GUY, T.; OLIVEIRA, M. A.. Aves do Brasil: Pantanal e Cerrado. São Paulo: Horizonte; Nova York: Comstock Publishing Associates. 2010.

IKIN, K.; KNIGHTM, E.; LINDENMAYER, D. B.; FISCHER, J.; MANNING, A. D.. The influence of native versus exotic streetscape vegetation on the spatial distribution of birds in suburbs and reserves. Diversity and Distributions, v.19, n.3, p.294-306, 2013. DOI: http://doi.org/10.1111/j.14724642.2012.00937.x

JESUS, S.; PEDRO; WAGNER, A.; BISPO, A.. Bird diversity along a gradient of fragmented habitats of the Cerrado. Anais da Academia Brasileira de Ciências, v.90, n.1, p.123135, 2018. DOI: http://doi.org/10.1590/0001$\underline{3765201720160383}$

JOKIMÄKI, J.; SUHONEN, J.. Distribution and habitat selection of wintering birds in urban environments. Landscape and Urban Planning, v.39, n.4, p.253-263, 1998. DOI: http://doi.org/10.1016/S0169-2046(97)00089-3

KANG, W.; MINOR, E. S.; PARK, C. R.; LEE, D.. Effects of habitat structure, human disturbance, and habitat connectivity on urban forest bird communities. Urban Ecosystems, v.18, n.3, p.857-870, 2015. DOI: http://doi.org/10.1007/s11252-014-0433-5

LIMA, R. C.; SILVA JÚNIOR, M. C.. Inventário da arborização urbana implantada na década de 60 no Plano Piloto, Brasília, DF. Revista Brasileira de Arborização Urbana, v.2, p.110127, 2010.

MACGREGOR-FORS, I.; ORTEGA-ÁLVAREZ, R.. Fading from the forest: Bird community shifts related to urban park sitespecific and landscape traits. Urban Forestry and Urban Greening, v.10, n.3, p.239-246, 2011. DOI: http://doi.org/10.1016/j.ufug.2011.03.004

MACGREGOR-FORS, I.; SCHONDUBE, J. E.. Gray vs. green urbanization: Relative importance of urban features for urban bird communities. Basic and Applied Ecology, v.12, n.4, p.372-381, 2012. DOI: http://doi.org/10.1016/i.baae.2011.04.003

MARGURRAN, A.. Ecological Diversity and its Measurement. Cambridge: British Library, 1988.

MARQUES, C. P.; AMARAL, D. F.; GUERRA, V.; FRANCHIN, A. G.; MARÇAL JÚNIOR, O. M.. Exploração de recursos alimentares por psitacídeos (Aves: Psittaciformes) em uma área urbana no Brasil. Biotemas, v.31, n.2, p.33-46, 2018. DOI: http://doi.org/10.5007/2175-7925.2018v31n2p33

MARTINS-OLIVEIRA, L.; LEAL-MARQUES, R.; NUNES, C. H.; FRANCHIN, A. G.; MARÇAL JÚNIOR, O. M.. Foraging behaviour of pitangus sulphuratus and tyrannus melancholicus (Aves: Tyrannidae) in urban habitats. Biosci. J., v.28, n.6, p.1038-1050, 2012. 
MARZLUFF, J. M.; BOWMAN, R.; DONNELLY, R.. A historical perspective on urban bird research: trends, terms, and approaches. Avian Ecology and Conservation in an Urbanizing World, p.1-17, 2001. DOI: http://doi.org/10.1007/978-1-4615-1531-9 1

MATSUBA, M.; NISHIJIMA, S.; KATOH, K.. Effectiveness of corridor vegetation depends on urbanization tolerance of forest birds in central Tokyo, Japan. Urban Forestry and Urban Greening, v.18, p.173-181, 2016. DOI: http://doi.org/10.1016/j.ufug.2016.05.011.

MCKINNEY, M. L.. Effects of human population, area, and time on non-native plant and fish diversity in the United States. Biological Conservation, v.100, n.2, p.243-252, 2001. DOI: http://doi.org/10.1016/S0006-3207(01)00027-1

MCKINNEY, M. L.. Effects of urbanization on species richness: A review of plants and animals. Urban Ecosystems, v.11, n.2, p.161-176, 2008. DOI: http://doi.org/10.1007/s11252-007-0045-4

MCKINNEY, M. L.. Urbanization, Biodiversity and Conservation. BioScience, v.52, n.10, p.883-890, 2002. DOI: http://doi.org/10.1641/0006-3568(2002)052

MELLES, S.; GLENN, S.; MARTIN, K.. Urban bird diversity and landscape complexity: Species-environment associations along a multiscale habitat gradient. Ecology and Society, v.7, n.1, 2003. DOI: http://doi.org/10.5751/ES-00478-070105

MENDONÇA, L. B.; ANJOS, L.. Beija-flores (Aves, Trochilidae) e seus recursos florais em uma área urbana do Sul do Brasil. Revista Brasileira de Zoologia, v.22, n.1, p.51-59, 2005. DOI: http://doi.org/10.1590/s0101-81752005000100007

MORELLI, F.; BEIM, M.; JERZAK, L.; JONES, D.; TRYJANOWSKI $P$.. Can roads, railways and related structures have positive effects on birds? - A review. Transport and Environment, v.30, p.21-31, 2014. DOI:

http://doi.org/10.1016/i.trd.2014.05.006

MURGUI, E.. Factors influencing the bird community of urban wooded streets along an annual cycle. Ornis Fennica, v.84, n.2, p.66-77, 2007

NEGRET, Á.. Fluxos migratórios na avifauna da reserva ecológica do IBGE, Brasília, D.F., Brasil. Revista Brasileira de Zoologia, v.5, n.2, p.209-214, 1988. DOI: http://doi.org/10.1590/S0101-81751988000200005

OKSANEN, J.; BLANCHET, F. G.; FRIENDLY, M.; KINDT, R.; LEGENDRE, P.; MCGLINN, D.; MINCHIN, P. R.; O'HARA, R. B.; SIMPSON, G. L.; SOLYMOS, P.; STEVENS, M. H. H.; SZOECS, E.; WAGNE, H.. Package 'vegan': Community Ecology Package. R package version 2.5-6. 2019.

OLIVEIRA, A. C.; KANEGAE, M. F.; AMARAL, M. F.; FÁVARO, F. L.. Guia Para Observação das Aves do Parque Nacional de Brasília. Brasília: ICMBio, 2011.

ORTEGA-ÁLVAREZ, R.; MACGREGOR-FORS, I.. Dusting-off the file: A review of knowledge on urban ornithology in Latin America. Landscape and Urban Planning, v.101, p.1-10, 2011. DOI:

http://doi.org/10.1016/i.landurbplan.2010.12.020
PENA, J. C. C.; MAGALHÃES, D. M.; MOURA, A. C. M.; YOUNG, R. J.; RODRIGUES, M.. Street trees reduce the negative effects of urbanization on birds. PLoS ONE, v.12, n.3, p.1-19, 2017. DOI: http://doi.org/10.1371/journal.pone.0174484

PIACENTINI, V. Q.; ALEIXO, A.; AGNE, C. E.; MAURICIO, G. N.; PACHECO, J. F.; BRAVO, G. A.; BRITO, G. R. R.; NAKA, L. N.; OLMOS, F.; POSSO, S., SILVEIRA, L. F.; BETINI, G. S.; CARRANO, E.; FRANZ, I.; LESS, A. C.; LIMA, L. M.; PIOLLI, D.; SCHUNCK, F.; AMARAL, F. R.; BENCKE, A. G.; COHN-HAFT, M.; FIGUEIREDO, L. F. A.; STRUBE, F. C.; CESARI, E.. Annotated checklist of the birds of Brazil by the Brazilian Ornithological Records Committee / Lista comentada das aves do Brasil pelo Comitê Brasileiro de Registros Ornitológicos. Revista Brasileira de Ornitologia, v.23, n.2, p.91-298, 2015.

PERILLO, A.; MAZZONI, L. G.; PASSOS, L. F.; GOULART, V. D. L. R.; DUCA, C.; YOUNG, R. J.. Anthropogenic noise reduces bird species richness and diversity in urban parks. lbis, v.159, n.3, p.638-646, 2017. DOI: https://doi.org/10.1111/ibi.12481

RALPH, C. J.; GEUPEL, G. R.; PYLE, P.; MARTIN, T. E.; DESANTE, D. F.. Handbook of Field Methods for Monitoring Landbirds. Director, v.144, n.1, p.1-41, 1993.

REIS, E.; LÓPEZ-IBORRA, G. M.; PINHEIRO, R. T.. Changes in bird species richness through different levels of urbanization: Implications for biodiversity conservation and garden design in Central Brazil. Landscape and Urban Planning, v.107, n.1, p.31-42, 2012. DOI: http://doi.org/10.1016/j.landurbplan.2012.04.009

RIBEIRO, J. F.; WALTER, B. M. T.. As principais fitofisionomias do bioma Cerrado in: SANO, S. M.; ALMEIDA, S. P.; RIBEIRO, J. F.. Cerrado Ecologia e Flora. Brasília: Embrapa Informação Tecnológica, 2008. p.556.

RICKLEFS, R. E.. Species richness and morphological diversity of passerine birds. Proceedings of the National Academy of Sciences of the United States of America, v.109, n.36, p.14482-14487, 2012. DOI:

http://doi.org/10.1073/pnas.1212079109

RODRIGUES, A. G.; BORGES-MARTINS, M.; ZILIO, F.. Bird diversity in an urban ecosystem: the role of local habitats in understanding the effects of urbanization. Iheringia. Série Zoologia, v.108, p.1-11, 2018. DOI: http://doi.org/10.1590/1678-4766e2018017

SACCO, A. G.; BERGMANN, F. B.; RUI, A. M.. Assembleia de aves na área urbana do município de Pelotas, Rio Grande do Sul, Brasil. Biota Neotropica, v.13, n.2, p.153-162, 2013. DOI: http://doi.org/10.1590/S1676-06032013000200014

SHIBUYA, F. L. S.; BRAGA, T. V.; ROPER, J. J.. The Rufous Hornero (Furnarius rufus) nest as an incubation chamber. Journal of Thermal Biology, v.47, p.7-12, 2015. DOI: http://doi.org/10.1016/j.jtherbio.2014.10.010

SICK, H.. Ornitologia Brasileira. Rio de Janeiro: Nova Fronteira, 1997.

SILVA, J. M.; BATES, J. M.. Biogeographic Patterns and Conservation in the South American Cerrado: A Tropical Savanna Hotspot. BioScience, v.52, n.3, p.225-233, 2002. 
SOL, D.; BARTOMEUS, I.; GONZÁLEZ-LAGOS, C.; PAVOINE, S.. Measuring tolerance to urbanization for comparative analyses. Ardeola, v.60, n.1, p.3-13, 2013. DOI: http://doi.org/10.13157/arla.60.1.2012.3

SOL, D.; GONZÁLEZ-LAGOS, C.; MOREIRA, D.; MASPONS, J.. Urbanisation and the loss of phylogenetic diversity in birds. Ecology Letters, v.20, n.6, p.721-729, 2017. DOI: http://doi.org/10.1111/ele.12769

SOUZA, F. L.; VALENTE-NETO, F.; SEVERO-NETO, F.; BUENO, B.; OCHOA-QUINTERO, J. M.; LAPS, R. R.; BOLZAN, F.; ROQUE, F. O.. Impervious surface and heterogeneity are opposite drivers to maintain bird richness in a Cerrado city.
Landscape and Urban Planning, v.192, n.2018, p.103-643, 2019. DOI:

http://doi.org/10.1016/i.landurbplan.2019.103643

TOLEDO, M. C. B.; DONATELLI, R. J.; BATISTA, G. T.. Relation between green spaces and bird community structure in an urban area in Southeast Brazil. Urban Ecosystems, v.15, n.1, p.111-131, 2012. DOI: http://doi.org/10.1007/s11252-011$\underline{0195-2}$

TUBELIS, D.; CAVALCANTI, R.. Community similarity and abundance of bird species in open habitats of a central Brazilian Cerrado. Ornitologia Neotropical, v.12, p.57-73, 2001.

A CBPC - Companhia Brasileira de Produção Científica (CNPJ: 11.221.422/0001-03) detém os direitos materiais desta publicação. Os direitos referem-se à publicação do trabalho em qualquer parte do mundo, incluindo os direitos às renovações, expansões e disseminações da contribuição, bem como outros direitos subsidiários. Todos os trabalhos publicados eletronicamente poderão posteriormente ser publicados em coletâneas impressas sob coordenação da Sustenere Publishing, da Companhia Brasileira de Produção Científica e seus parceiros autorizados. Os (as) autores (as) preservam os direitos autorais, mas não têm permissão para a publicação da contribuição em outro meio, impresso ou digital, em português ou em tradução. 